\title{
Long-Term Outcome of Primary Endoscopic Realignment for Bulbous Urethral Injuries: Risk Factors of Urethral Stricture
}

\author{
Ill Young Seo, Jea Whan Lee, Seung Chol Park, Joung Sik Rim \\ Department of Urology, Wonkwang University School of Medicine, Iksan, Korea
}

\begin{abstract}
Purpose: Although endoscopic realignment has been accepted as a standard treatment for urethral injuries, the long-term follow-up data on this procedure are not sufficient. We report the long-term outcome of primary endoscopic realignment in bulbous urethral injuries.

Methods: Patients with bulbous urethral injuries were treated by primary endoscopic realignment between 1991 and 2005. The operative procedure included suprapubic cystostomy and transurethral catheterization using a guide wire, within 72 hours of injury. The study population included 51 patients with a minimum follow-up duration of 5 years.

Results: The most common causes of the injuries were straddle injury from falling down (74.5\%), and pelvic bone fracture (7.8\%). Gross hematuria was the most common complaint (92.2\%). Twenty-three patients (45.1\%) had complete urethral injuries. The mean time to operation after the injury was $38.8 \pm 43.2$ hours. The mean operation time and mean indwelling time of a urethral Foley catheter were $55.5 \pm 37.6$ minutes and $22.0 \pm 11.9$ days, respectively. Twenty out of 51 patients $(39.2 \%)$ were diagnosed with urethral stricture in $89.1 \pm 36.6$ months after surgery. A multivariate analysis revealed that young age and operation time were independent risk factors for strictures as a complication of urethral realignment (hazard ratio [HR], 6.554, $\mathrm{P}=0.032 ; \mathrm{HR}, 6.206$, $\mathrm{P}=0.035)$.

Conclusions: Urethral stricture commonly developed as a postoperative complication of primary endoscopic urethral realignment for bulbous urethral injury, especially in young age and long operation time.
\end{abstract}

Keywords: Urethra; Wounds and injuries; Risk factors

\section{INTRODUCTION}

Bulbous urethral injury (BUI), which usually occurs as a result of straddle injury, is more common than posterior urethral injury [1]. The key to successful management of a BUI is the maintenance of urethral continuity while minimizing the risk of complications [2]. The timing of and methods used for the treatment continues to be debated. Numerous reports on primary endoscopic realignment have supported this approach as the treatment modality for patients with urethral injuries; however, the long-term follow-up data on this procedure are not sufficient [3-5].

We report the results of primary endoscopic realignment of
BUI, with a minimum follow-up of 5 years, and the risk factors predicting urethral stricture as an operative complication.

\section{MATERIALS AND METHODS}

The diagnosis of urethral injury was established by routine retrograde urethrography (RGU). All patients with BUI were treated with primary endoscopic urethral realignment within 72 hours of injury. The operative procedure included a suprapubic cystostomy. A flexible cystourethroscope was inserted through the cystostomy tract, and a 0.035 -inch guide wire was passed carefully in an antegrade direction through a flexible cystourethroscope down the bladder neck and prostatic urethra. A rigid
Corresponding author: Ill Young Seo

Department of Urology, Wonkwang University School of Medicine \& Hospital, Institute of Wonkwang Medical Science, 895 Muwang-ro, Iksan 570-974, Korea Tel: +82-63-859-1333, Fax: +82-63-842-1455, E-mail: seraph@wonkwang.ac.kr Submitted: October 21, 2012 / Accepted after revision: December 4, 2012
This is an Open Access article distributed under the terms of the Creative Commons Attribution Non-Commercial License (http://creativecommons.org/licenses/by-nc/3.0/) which permits unrestricted non-commercial use, distribution, and reproduction in any medium, provided the original work is properly cited. 
cystourethroscope was inserted into the anterior urethra. The guide wire was pulled out using forceps, and a $20 \mathrm{~F}$ urethral Foley catheter was inserted over the guide wire. A second Foley catheter was inserted into the bladder through the cystostomy tract.

Ninety-one patients with bulbous urethral injuries were presented in our hospital from January 1991 to December 2005. Seventy patients were treated with primary endoscopic realignment. Among of them, 51 patients were followed-up more than 5 years and included in this study. If the patients had suffered severe pelvic bone injury or contraindication of anesthesia, we should have performed a delay operation with open technique.

All operations were performed by one urologist. The mean patient age at surgery was $47.8 \pm 15.2$ years (range, 23 to 70 years). The most common cause of the BUI was straddle injury from falling down (38 patients, $74.5 \%$ ), followed by iatrogenic trauma, human violence, and traffic accidents. Several pelvic-organ injuries, including pelvic bone fracture (7.8\%), scrotal and perineal hematomas, testicular injury, and major soft-tissue defects, were associated. The chief urologic complaints were gross hematuria in 47 patients $(92.2 \%)$ and urinary retention in 4 patients. The degree of injury was classified on the basis of the RGU findings. The injury was defined as a partial urethral injury if, as observed on a urethrogram, the contrast material extravasat- ed although the continuity of the urethra was maintained, and as a complete urethral injury if the continuity of the urethra was disrupted and the contrast material was not observed in the proximal urethra (Fig. 1). Twenty-eight patients (54.9\%) had partial urethral injuries, and 23 patients (45.1\%) had complete urethral injuries (Table 1).

We retrospectively collected the data of patients who were followed up for a minimum of 5 years. The data of patients having urethral stricture, a complication of endoscopic urethral realignment, were assessed, and the risk factors predicting the incidence of urethral stricture were analyzed by bivariate analyses using Levene's test and multivariate analyses using binary logistic regression. All statistical analyses were performed with the use of the statistical software program PASW ver. 18.0 (IBM Co., Armonk, NY, USA), and a P-value of $<0.05$ was considered statistically significant.

\section{RESULTS}

Primary endoscopic realignment for patients with BUI could be performed safely; no patient required conversion to open surgery. The mean time to the operation after injury was $38.8 \pm 43.2$ hours (range, 4 to 196 hours). The mean operation time was $55.5 \pm 37.6$ minutes (range, 20 to 160 minutes), which was de-
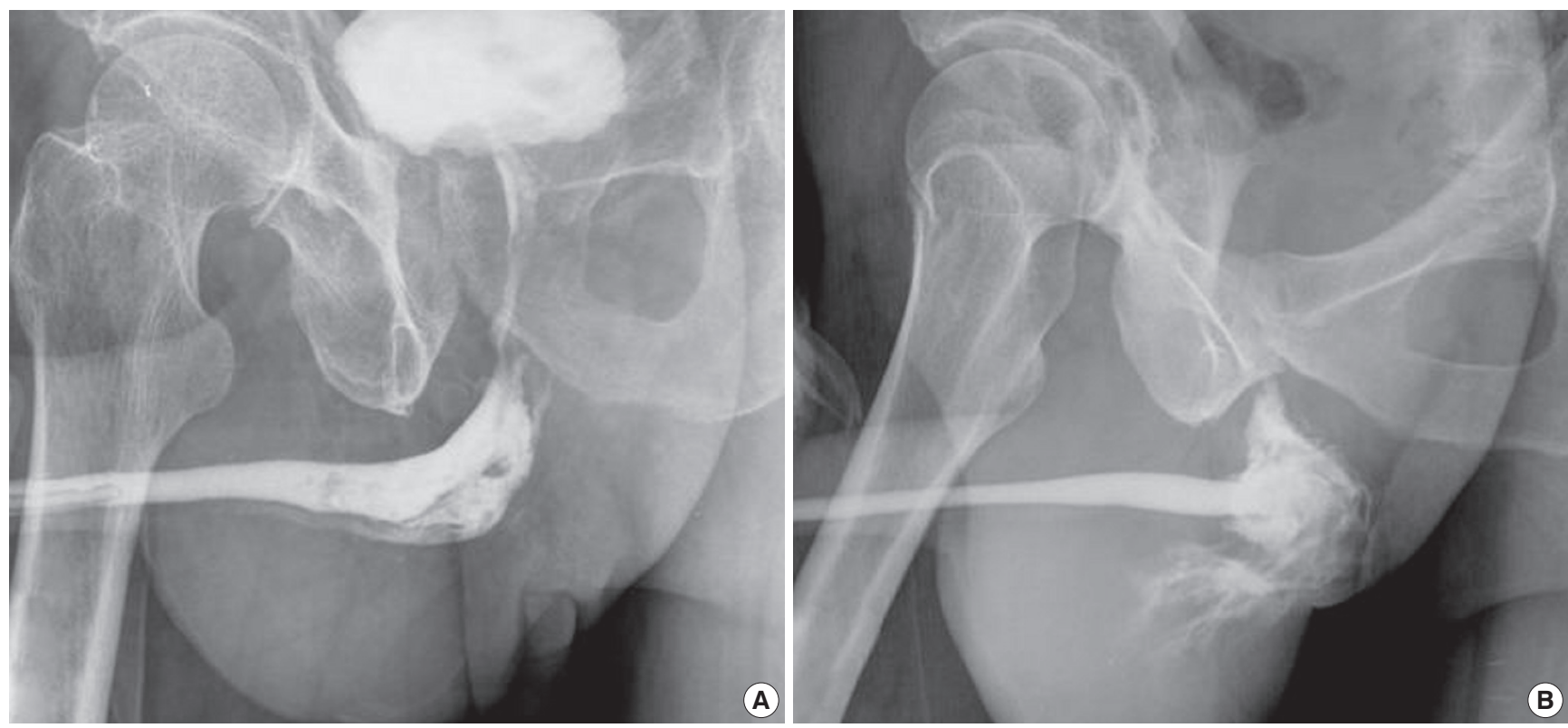

Fig. 1. Retrograde urethrograms. (A) Partial urethral injury, with resulting partial disruption of the bulbous urethra demonstrating venous intravasation. (B) Complete urethral injury, with contrast extravasation from the bulbar urethra throughout the perineum, with no filling of the proximal urethra and bladder. 
Table 1. Clinical characteristics of 51 patients with bulbous urethral injuries

\begin{tabular}{lc}
\hline Characteristic & No. of patients (\%) \\
\hline Cause of injury & $38(74.5)$ \\
Falls & $5(9.8)$ \\
Iatrogenic & $4(7.8)$ \\
Human violence & $2(3.9)$ \\
Traffic accident & $2(3.9)$ \\
Others & \\
Associated pelvic organ injury & $4(7.8)$ \\
Pelvic bone fracture & $4(7.8)$ \\
Scrotal \& perineal hematoma & $2(3.9)$ \\
Testicular injury & $2(3.9)$ \\
Major soft tissue defect & \\
Urologic chief complaints & $47(92.2)$ \\
Gross hematuria & $4(7.8)$ \\
Urinary retention & \\
Degree of urethral injury & $28(54.9)$ \\
Partial BUI & $23(45.1)$ \\
Complete BUI & \\
\hline
\end{tabular}

BUI, bulbous urethral injury.

fined as the time from the suprapubic cystostomy to insertion of the urethral Foley catheter. The mean indwelling time of the urethral Foley catheter was $22.0 \pm 11.9$ days (range, 6 to 63 days). Our intended time of the urethral Foley catheter was 7 days for partial injury and 14 days for complete injury. However, if the patients with pelvic bone fracture had kept in bed-resting state, the indwelling time could be prolonged. Before removal of the Foley catheter, a pericatheter urethrography was performed to identify if urinary extravasation had occurred. In addition, uroflowmetry was conducted after the removal of the urethral catheter. The mean maximal flow rate was $18.6 \pm 8.5 \mathrm{~mL} / \mathrm{sec}$ (range, 5.0 to $39.5 \mathrm{~mL} / \mathrm{sec}$ ). The mean follow-up duration was $89.1 \pm$ 36.6 months (range, 60 to 176 months).

During the follow up, 20 patients (39.2\%) developed urethral strictures, which were initially diagnosed by uroflowmetry (less than $10 \mathrm{~mL} / \mathrm{sec}$ of maximal flow rate) or cystourethroscopy. The mean time between the injury and the development of stricture was $3.7 \pm 3.1$ months (range, 1 to 13 months). Most of the strictures developed in the first year. The mean stricture length was $0.91 \pm 0.47 \mathrm{~cm}$ (range, 0.3 to $1.8 \mathrm{~cm}$ ), as determined from the retrograde urethrogram. Strictures were managed by open urethroplasty in 4 patients (20\%), internal urethrotomy in 3 pa- tients (15\%), urethral sound dilation in 7 patients (35\%), and conservative management in 6 patients (30\%). Four patients (20\%) complained of voiding difficulty at the last visit.

Clinical and operative characteristics were assessed to identify the risk factors predicting urethral stricture as a complication of endoscopic urethral realignment. A multivariate analysis was performed for 20 patients with urethral stricture (group 1), and 31 patients without urethral stricture (group 2). Seven parameters were assessed for statistical significance. Young age (less than 60 years) and long operation time (more than 30 minutes) were independent risk factors in the results of long-term follow-up in the multivariate analyses using binary logistic regression (hazard ratio $[\mathrm{HR}], 6.554, \mathrm{P}=0.032 ; \mathrm{HR}, 6.206, \mathrm{P}=0.035$ ) (Table 2).

\section{DISCUSSION}

Anterior urethral injuries, mostly those to the bulbar urethra, are caused by blunt trauma, including straddle injuries $[1,6]$. Although these injuries are commonly associated with a urethral wall contusion or a partial urethral injury, complete urethral disruption is rare [7].

The method of managing patients with BUI continues to be debated. Some urologists prefer delayed reconstruction with a suprapubic cystostomy because of the associated injuries and concomitant contusion of the supporting spongiosum. The preferred form of surgery is generally an open repair, which should be performed several weeks or months after cystostomy to allow the urethra to stabilize $[6,8]$. However, according to some reports, primary surgical repair has better outcomes in patients with BUI $[5,9,10]$. If there is a contusion or a partial BUI, it can be monitored or treated with transurethral catheterization. For patients with a partial injury, primary transurethral catheterization may be performed as the initial step [5]. If this is not possible, a suprapubic cystostomy is needed to prevent additional urethral damage [11]. For more complex or complete disruption, endoscopic realignment or open urethroplasty is required.

Primary endoscopic realignment has been considered as a standard treatment for patients with urethral injuries. Several techniques are available for successful endoscopic realignment $[11,12]$. Cohen et al. [13] used a flexible cystoscope to identify the bladder neck and a fluoroscope to guide the advancement of the instrument. Gelbard et al. [14] used a technique in which a Goodwin urethral sound was advanced into the bladder neck and urethra, and the tip of the Goodwin sound could be detected by the cystoscopist. Porter et al. [15] also reported that coax- 
Table 2. Multivariate analysis of factors predicting urethral stricture in patients with endoscopic urethral realignments

\begin{tabular}{|c|c|c|c|c|c|c|c|c|}
\hline \multirow{2}{*}{ Risk factor } & \multicolumn{2}{|c|}{ No. of patients } & \multicolumn{3}{|c|}{ Bivariate analysis } & \multicolumn{3}{|c|}{ Multivariate analysis } \\
\hline & Group 1 & Group 2 & HR & $95 \% \mathrm{CI}$ & P-value & HR & $95 \% \mathrm{CI}$ & P-value \\
\hline \multicolumn{9}{|l|}{ Age (yr) } \\
\hline$\geq 60$ & 3 & 13 & & & & & & \\
\hline$<60$ & 17 & 18 & 2.174 & $0.007-0.531$ & 0.044 & 6.554 & $1.172-36.655$ & 0.032 \\
\hline \multicolumn{9}{|c|}{ Straddle injury } \\
\hline No & 5 & 8 & & & & & & \\
\hline Yes & 15 & 23 & 0.016 & $0.248-0.266$ & 0.950 & 1.092 & $0.217-5.494$ & 0.915 \\
\hline \multicolumn{9}{|c|}{ Pelvic bone fracture } \\
\hline No & 18 & 29 & & & & & & \\
\hline Yes & 2 & 2 & 0.814 & $0.1222-0.193$ & 0.653 & 0.493 & $0.050-4.891$ & 0.546 \\
\hline \multicolumn{9}{|c|}{ Gross hematuria } \\
\hline No & 2 & 2 & & & & & & \\
\hline Yes & 8 & 9 & 0.814 & $0.131-0.202$ & 0.653 & 0.372 & $0.035-3.927$ & 0.411 \\
\hline \multicolumn{9}{|c|}{ Degree of urethral injury } \\
\hline Partial & 9 & 19 & & & & & & \\
\hline Complete & 11 & 12 & 0.589 & $0.126-0.451$ & 0.263 & 2.292 & $0.489-10.744$ & 0.293 \\
\hline \multicolumn{9}{|c|}{ Time to operation (hr) } \\
\hline$<24$ & 10 & 14 & & & & & & \\
\hline$\geq 24$ & 10 & 17 & 0.182 & $0.245-0.342$ & 0.742 & 1.557 & $0.388-6.255$ & 0.532 \\
\hline \multicolumn{9}{|c|}{ Operation time (min) } \\
\hline$<30$ & 3 & 14 & & & & & & \\
\hline$\geq 30$ & 17 & 17 & 6.035 & $0.038-0.564$ & 0.026 & 6.206 & $1.139-33.822$ & 0.035 \\
\hline \multicolumn{9}{|c|}{ Indwelling time of urethral FC (day) } \\
\hline$<14$ & 5 & 10 & & & & & & \\
\hline$\geq 14$ & 15 & 21 & 1.281 & $0.195-0.339$ & 0.582 & 0.570 & $0.108-2.999$ & 0.507 \\
\hline
\end{tabular}

Group 1, patients with urethral stricture (20 patients); Group 2, patients without urethral stricture (31 patients); HR, hazard ratio; CI, confidence interval; FC, Foley catheter.

ial magnetic urethral catheters could be used successfully. We treated all patients with BUI with primary endoscopic urethral realignment within 72 hours of the initial injury. All patients had a suprapubic cystostomy as a working tract. The $16 \mathrm{~F}$ flexible cystourethroscope and guide wire were inserted through the cystostomy tract, and the course of the rigid cystourethroscope from the urethral meatus was guided by the light of the flexible cystourethroscope.

Although numerous reports have shown the operative results of a primary endoscopic realignment for patients with urethral injuries, the long-term follow-up data on this procedure are not sufficient. The development of a postrealignment urethral stricture is a major complication, and it is important to clarify the severity of the stenosis. In a study by Ying-Hao et al. [5], the frequency of urethral strictures developing immediately after urethroscopic realignment of a ruptured bulbar urethra was reported to be $12.5 \%$ in 16 men, with a mean follow-up duration of 56 months, and in another study by Ku et al. [9], it was reported to be $18.5 \%$ in 65 patients, with a mean follow-up duration of 28.2 months. Park et al. [16] studied the 5-year followup results of endoscopic realignment in 11 patients with anterior urethral injuries and found that 6 patients (54\%) had urethral stricture necessitating internal urethrotomy and sound dilation. Our study also showed a relatively high incidence of urethral stricture, i.e., $39.2 \%$. The strictures were treated by open urethroplasty, internal urethrotomy, and urethral metal sound dilation. However, 4 patients (20\%) complained a voiding difficulty even after treatment. 
Few studies have identified factors that may affect the outcome of endoscopic realignment in patients with BUI. Park and McAninch [4] reported the outcomes in 78 patients with BUI. They found no relationship between urethral stricture length and the mechanism of injury or initial management technique. We therefore aimed at identifying risk factors predicting the urethral stricture as a complication of the endoscopic urethral realignment. Our multivariate analysis revealed that young age (less than 60 years) and long operation times (more than 30 minutes) were independent risk factors. Close follow-up after urethral realignment is recommended for patients with these risk factors. We assumed that young-aged person may have more severe injury due to physical activity. However, number of patients with complete injury was $15(42.9 \%)$ in young-aged group and $8(50.0 \%)$ in old-aged group, and number of patients with pelvic bone fracture was $4(15.4 \%)$ and $0(0 \%)$. There were no statistical difference on Fisher's exact test $(\mathrm{P}=0.430$ and 0.134$)$. We also assumed that long operation time may be related to the degree of injury and pelvic bone fracture. Number of patients with complete injury was 6 (35.3\%) in short operation time group and 17 (50.0\%) in long operation time group, and number of patients with pelvic bone fracture was $0(0 \%)$ and $4(11.8 \%)$. There were no statistical difference as well $(\mathrm{P}=0.244$ and 0.186$)$.

Our study has several limitations. The sample size available for studying long-term results was small. Additionally, we could not compare the results of primary endoscopic urethral realignment to those of a delayed operation or open urethroplasty.

In conclusion, the results of a long-term follow up of over 5 years showed that primary endoscopic urethral realignment is a simple and safe therapeutic modality for BUI. However, urethral stricture was a complication, and young age and long operation times are risk factors predicting the incidence of urethral stricture. Additional studies with a large number of patients are needed to identify a method for minimizing these complications.

\section{CONFLICT OF INTEREST}

No potential conflict of interest relevant to this article was reported.

\section{REFERENCES}

1. Kommu SS, Illahi I, Mumtaz F. Patterns of urethral injury and immediate management. Curr Opin Urol 2007;17:383-9.

2. Chapple C, Barbagli G, Jordan G, Mundy AR, Rodrigues-Netto N, Pansadoro V, et al. Consensus statement on urethral trauma. BJU Int 2004;93:1195-202.

3. Pontes JE, Pierce JM Jr. Anterior urethral injuries: four years of experience at the Detroit General Hospital. J Urol 1978;120:563-4.

4. Park S, McAninch JW. Straddle injuries to the bulbar urethra: management and outcomes in 78 patients. J Urol 2004;171(2 Pt 1):722-5.

5. Ying-Hao S, Chuan-Liang X, Xu G, Guo-Qiang L, Jian-Guo H. Urethroscopic realignment of ruptured bulbar urethra. J Urol 2000;164: 1543-5.

6. Hernandez J, Morey AF. Anterior urethral injury. World J Urol 1999; 17:96-100.

7. Dobrowolski ZF, Weglarz W, Jakubik P, Lipczynski W, Dobrowols$\mathrm{ka}$ B. Treatment of posterior and anterior urethral trauma. BJU Int 2002;89:752-4.

8. Morey AF, Duckett CP, McAninch JW. Failed anterior urethroplasty: guidelines for reconstruction. J Urol 1997;158:1383-7.

9. Ku Ja, Kim ME, Jeon YS, Lee NK, Park YH. Management of bulbous urethral disruption by blunt external trauma: the sooner, the better? Urology 2002;60:579-83.

10. Nakajima K, Deguchi M, Ishii N, Kawakami T, Nozawa E, Hara H, et al. Endoscopic management of a traumatic disruption of the bulbous urethra using a thin trocar puncture. Int J Urol 2001;8:202-4.

11. Madani AH, Dezhabad V. Early endoscopically guided catheterization as primary treatment for realignment of ruptured anterior urethra. BJU Int 2002;90(Suppl 2):49.

12. Elliott DS, Barrett DM. Long-term followup and evaluation of primary realignment of posterior urethral disruptions. J Urol 1997; 157:814-6.

13. Cohen JK, Berg G, Carl GH, Diamond DD. Primary endoscopic realignment following posterior urethral disruption. J Urol 1991;146: 1548-50.

14. Gelbard MK, Heyman AM, Weintraub P. A technique for immediate realignment and catheterization of the disrupted prostatomembranous urethra. J Urol 1989;142:52-5.

15. Porter JR, Takayama TK, Defalco AJ. Traumatic posterior urethral injury and early realignment using magnetic urethral catheters. J Urol 1997;158:425-30.

16. Park CS, Park SW, Kim JM, Lee JZ. 5 year follow-up results of endoscopic primary realignment in urethral injury. Korean J Urol 2007; 48:1165-70. 